\title{
Malaria Knowledge, Concern, Land Management, and Protection Practices among Land Owners and/or Managers in Lowland versus Highland Ecuador
}

\author{
Lauren L. Pinault and Fiona F. Hunter \\ Department of Biological Sciences, Brock University, 500 Glenridge Avenue, St. Catharines, ON, Canada L2S 3A1 \\ Correspondence should be addressed to Lauren L. Pinault, lauren.pinault@gmail.com
}

Received 30 June 2011; Revised 27 November 2011; Accepted 21 December 2011

Academic Editor: Polrat Wilairatana

Copyright ( $) 2011$ L. L. Pinault and F. F. Hunter. This is an open access article distributed under the Creative Commons Attribution License, which permits unrestricted use, distribution, and reproduction in any medium, provided the original work is properly cited.

\begin{abstract}
To control malaria effectively, it is essential to understand the current knowledge, beliefs, concerns, land management practices, and mosquito bite protection methods in use by citizens. This study presents a comparative, quantitative, interview-based study of land owners and/or managers $(n=262)$ in the Ecuadorian lowlands (presently considered malarious) $(n=131)$ and highlands (potentially malarious in the future) $(n=131)$. Although respondents had a strong understanding of where the disease occurs in their own country and of the basic relationship among standing water, mosquitoes, and malaria, about half of respondents in potential risk areas denied the current possibility of malaria infection on their own property. As well, about half of respondents with potential anopheline larval habitat did not report its presence, likely due to a highly specific definition of suitable mosquito habitat. Most respondents who are considered at risk of malaria currently use at least one type of mosquito bite prevention, most commonly bed nets.
\end{abstract}

\section{Introduction}

Malaria remains a significant, debilitating and often lethal disease in many parts of South America, although its incidence, severity and impact is highly regional-dependent $[1,2]$. In lowland Colombia, for example, malaria has been rated by focus groups as one of the most important health problems facing communities [3]. In Colombian and Ecuadorian communities, the cost of malaria prevention is much less expensive than the sum of direct costs (e.g., treatment, travel) and indirect costs (e.g., days of work lost) [4]. In both countries, national malaria control programs monitor the disease and carry out mosquito control programs in malaria endemic areas $[5,6]$. Due to the success of these programs, statistics in Ecuador indicate that overall malaria incidence has declined over the last fifteen years, with occasional regional-scale epidemics at lower elevations (ca. < $1500 \mathrm{~m}$ ) [7].

At higher elevations, malaria was epidemic in the Inter-Andean valleys of Ecuador $(>1500 \mathrm{~m})$ prior to the mid-1940s, when large-scale eradication efforts prevented ongoing malaria transmission in these regions, mainly through the reduction and possible elimination of local populations of Anopheles pseudopunctipennis [8]. Since that time, malaria has only caused illness in highland regions among migrants and travelers returning from low altitudes $[1,7]$. Several reviews of the effects of various forms of global change on the incidence of insect-borne disease have stressed that malaria might move into higher-altitude regions as highland habitats become increasingly suitable for Anopheles mosquitoes [9-14]. Indeed, highland malaria has recently been observed in higher-altitude regions of Kenya, Rwanda, and Uganda [15-17], as well as in Andean Bolivia [18, 19]. Plasmodium vivax has been incriminated as the parasite in highland malaria epidemics in both 1940s Ecuador and recently in Bolivia $[8,18]$. Additionally, recent widespread highland records of three coastal malaria vectors: Anopheles albimanus, An. pseudopunctipennis, and Anopheles punctimacula, and one Amazonian vector, Anopheles oswaldoi s.l., provide support for the possibility of future highland malaria epidemics [20]. 
In Africa, it is believed that in higher-altitude regions, residents and health care practitioners may lack experiential knowledge of the disease and therefore do not know how to recognize malaria or protect themselves from mosquito bites [16]. As well, a person's experience with malaria could potentially raise a greater perception of malaria risk. Therefore, highland communities may not rate malaria risk strongly or recognize symptoms in order to seek treatment [21]. Residents may also not approach mosquito habitat elimination and personal mosquito bite protection as seriously as residents of malaria-endemic lower altitudes.

Although there is essentially no data regarding the perceptions of malaria in the South American Andes, there have been several studies conducted in lower-altitude regions. The knowledge of a connection between mosquito bites and malaria is regionally variable, for example, $56 \%$ of respondents in a rural community in northern coastal Ecuador versus $85 \%$ of respondents in an urban community in Pacific coastal Colombia [3, 22]. In Colombia, malaria has been inaccurately attributed to strenuous activities, ingesting hot foods, poor nutrition, drinking contaminated water, and/or proximity to garbage [23]. Individual differences in knowledge and perceptions have also been attributed to gender, with women having limited access to malariarelevant information and treatment, among other factors [24]. Malaria prevention in Colombia incorporates both modern techniques (e.g., bed nets and anopheline mosquito larval habitat elimination) as well as traditional techniques more commonly used in rural areas [3, 23, 25]. Urban residents in Amazonian Colombia also have been reported to feel less at risk of malaria than rural residents [23].

Malaria diagnosis by national bodies in South America is often based on passive reporting [25], where misdiagnosis of malaria could lead to a general underreporting of the disease over the landscape. The actual risk and occurrence of malaria in lowlands is complicated by human migration patterns between endemic and nonendemic regions, as well as by proximity to mosquito breeding sites [26].

Landowners and land managers, rather than lower-status workers, have the capability to eliminate anopheline larval habitats on their property and to promote and enforce the use of malaria control measures such as bed nets among their families and employees. In this study, a quantitative KAP (knowledge, attitudes and practices) approach was used to assess the degree of knowledge, concerns and beliefs of land managers and landowners in both lowland and highland regions of Ecuador for topics relevant to malaria prevention. The larval habitat management practices used and motivations for eliminating larval habitat were also examined. Finally, the study assessed mosquito bite protection that is currently in use in both lowland and highland regions and compared it to protection that would be used by respondents for hypothetical travel to a known malaria-endemic area.

\section{Materials and Methods}

To assess the knowledge, beliefs, concerns, land management practices, and forms of bite protection used by Ecuadorian land owners and/or managers, researchers conducted a series of 262 structured, questionnaire-based interviews of these individuals throughout all road-accessible regions of Ecuador between 2008 and 2010 (Figure 1). Most questionnaires were administered during the period from July to December in 2009 and 2010. Although the regions are endemic for malaria, we did not assess respondents in northern Esmeraldas, Sucumbíos, and Orellana provinces due to travel safety regulations (Figure 1). We attempted to eliminate clustering of respondents by traveling along as many different roads as possible. However, some clusters of respondents occurred (e.g., in Pichincha and Santo Domingo provinces) due to a higher number of potential respondents present outside their homes at the time of visiting, as well as a greater population and road density in that particular lowland-highland transition area, which may have led to a regional bias in our analysis (Figure 1).

To permit statistical inference, we interviewed a preestablished number of land owners and/or managers from each of five generalized land uses: cattle pasture (whether for meat or dairy), fish farms, plantations, human residences, and nature reserves. Fish farm and nature reserve managers were given fewer interviews than the other categories since they were encountered less frequently (Table 1). No more than one person was interviewed on the same property for the same land use. Although all five land use categories are present in all general regions of the country, there is some clustering of land uses in particular regions which may have caused small levels of spatial bias due to availability (Figure 1).

Land owners and managers were stratified on a second level by gender since women and men are expected to have different access to information and women may more readily apply knowledge toward prevention and treatment than men [24] (Table 1). Although we attempted to interview an equal number of men and women, we were not able to interview many female owners or managers of nature reserves due to the scarcity of women encountered in these positions (Table 1).

We further stratified interviews by interviewing an approximately equal number of landowners and/or managers above and below $1500 \mathrm{~m}$ (Table 1), which travel medical literature suggests as an appropriate altitudinal division for malaria endemism in Ecuador [27]. Current statistics from the Sistema Nacional de Eradicación de Malaria (SNEM) indicate that almost all areas below $1500 \mathrm{~m}$ have been affected by at least occasional cases of malaria during the last 10 years (Figure 1) [7], which we assume should have provided residents of the below $1500 \mathrm{~m}$ category with some experiential knowledge of malaria. Entomological data further supports this altitudinal risk division, since densities of Anopheles mosquitoes (malaria vectors) are more prevalent below $1500 \mathrm{~m}$, although a few larvae have been collected up to an elevation of nearly $2000 \mathrm{~m} \mathrm{[20].} \mathrm{This} \mathrm{alti-}$ tudinal division was used rather than actual reported malaria rates, since the distribution of malaria varies substantially from year to year, data comes from urban reporting centers rather than rural communities, and we expect rural parts of the country to underreport malaria cases due to poorer 


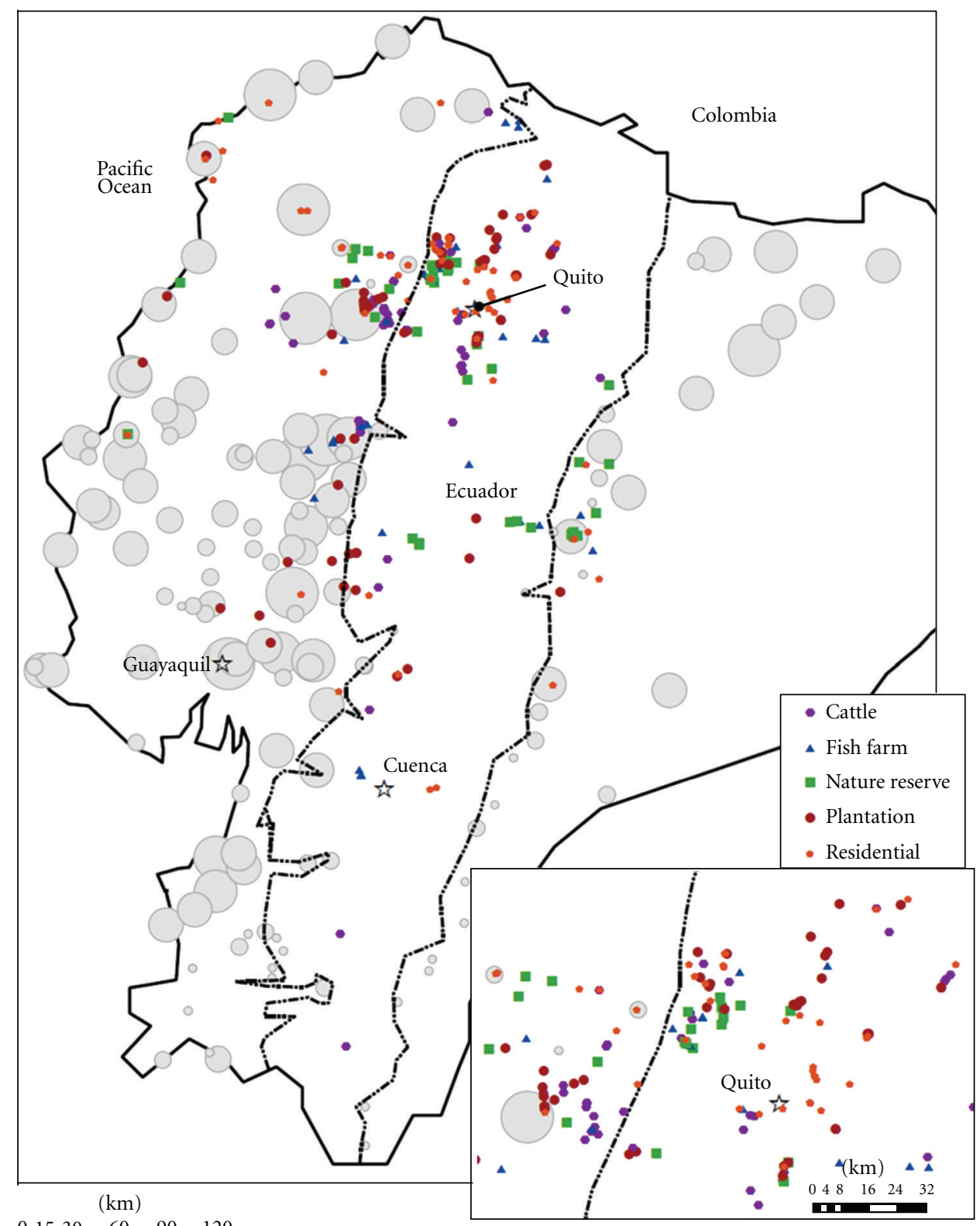

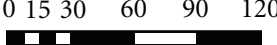

FIGURE 1: Map of interview localities $(n=262)$ in Ecuador, plotted by five general land use types (see legend). The numbers of cases of malaria recorded in population centers during the last 11 recorded years are indicated by progressively larger grey circles, where the smallest circles are 1-49 malaria cases and the largest are 10000-40000 cases (Source: SNEM Ecuador, 1997-2008 [7]), demonstrating that all cases were recorded below the $1500 \mathrm{~m}$ altitudinal division (hatched line). Inset: detail of interview localities near Quito, Ecuador. Map prepared using ArcGIS v.10 software (ESRI 2010).

access to health centres. Therefore, for the purposes of this study we also assume that all respondents below this altitude are potentially at risk for malaria.

To locate possible respondents, researchers working in groups of two or three traveled along all roads deemed suitable for travel and potential respondents were approached when visible from the road or other public domain. To introduce randomization, after spotting a potential respondent for a given land use, a coin toss was used to determine if the person would be approached. However, due to the scarcity of fish farm and nature reserve managers/owners, all of these possible respondents were approached when observed. Often, the land owner and/or manager was not present and the researchers did not interview any person on the site.

To avoid a possible feeling of deference toward the interviewer due to any perceived class differences, for example, [28], questionnaires were conducted by L. Pinault as well as one or two Ecuadorian interviewers who spoke the local dialects (although all field researchers spoke fluent Spanish) and a few contradictory statements were placed 
TABLE 1: Summary of sample sizes for interview respondents from 2008 to 2010, in Ecuador. Numbers of respondents are provided for land uses (cattle farm, plantation, residence, fish farm, and nature reserve), genders, and altitude categories (above/below $1500 \mathrm{~m}$ ).

\begin{tabular}{|c|c|c|c|c|c|}
\hline Land use & Number & Gender & Number & $\begin{array}{l}\text { Altitude } \\
\text { Category }\end{array}$ & Number \\
\hline \multirow{4}{*}{ Cattle } & \multirow{4}{*}{60} & \multirow{2}{*}{ Female } & \multirow{2}{*}{30} & Above & 15 \\
\hline & & & & Below & 15 \\
\hline & & \multirow{2}{*}{ Male } & \multirow{2}{*}{30} & Above & 15 \\
\hline & & & & Below & 15 \\
\hline \multirow{4}{*}{ Plantation } & \multirow{4}{*}{60} & \multirow{2}{*}{ Female } & \multirow{2}{*}{30} & Above & 15 \\
\hline & & & & Below & 15 \\
\hline & & \multirow{2}{*}{ Male } & \multirow{2}{*}{30} & Above & 15 \\
\hline & & & & Below & 13 \\
\hline \multirow{4}{*}{ Residence } & \multirow{4}{*}{62} & \multirow{2}{*}{ Female } & \multirow{2}{*}{31} & Above & 16 \\
\hline & & & & Below & 15 \\
\hline & & \multirow{2}{*}{ Male } & \multirow{2}{*}{31} & Above & 15 \\
\hline & & & & Below & 16 \\
\hline \multirow{4}{*}{ Fish farm } & \multirow{4}{*}{40} & \multirow{2}{*}{ Female } & \multirow{2}{*}{18} & Above & 7 \\
\hline & & & & Below & 11 \\
\hline & & \multirow{2}{*}{ Male } & \multirow{2}{*}{22} & Above & 13 \\
\hline & & & & Below & 9 \\
\hline \multirow{4}{*}{$\begin{array}{l}\text { Nature } \\
\text { reserve }\end{array}$} & \multirow{4}{*}{40} & \multirow{2}{*}{ Female } & \multirow{2}{*}{10} & Above & 5 \\
\hline & & & & Below & 5 \\
\hline & & \multirow{2}{*}{ Male } & \multirow{2}{*}{30} & Above & 15 \\
\hline & & & & Below & 15 \\
\hline
\end{tabular}

into the interview to identify respondents who might not be answering truthfully or might not understand the questions (e.g., all affirmative answers). Questions were asked directly in Spanish by both interviewers to respondents, rather than through translation to English. Yes and no questions were also placed in random order on the questionnaire. Voluntary participation and oral consent were received after researchers explained the study, including rights to withdraw at any stage during the interview process. All research was approved Brock University's Ethics in Human Research Committee, file number 07-336.

Aspects of the interview included: (1) knowledge of where malaria occurs in Ecuador, (2) knowledge of the ecological relationship among standing water and mosquitoes, and malaria, (3) belief in climate change, and belief that climate change could potentially cause malaria vectors to move into higher altitudes, (4) concern about insect-borne disease, the presence of mosquitoes on their property, and the presence of malaria on their property, (5) land management practices for standing water (mosquito habitat) reduction, and (6) mosquito bite protection used and bite protection that respondents would use to travel to an area known to have malaria. Researchers also recorded the geographic coordinates and elevation of the site using a handheld GPS unit (Garmin GPS e-Trex Summit).

Answers were translated from Spanish to English by L. Pinault. Respondents answered most questions with the options: yes (1) or no (0). To determine the role of altitudinal category and gender on the frequency of positive answers, a Binary Logistic Regression (Logit) was used. Those who answered "do not know" or "maybe" were considered uncertain answers and were eliminated from analysis when they were reported less than $10 \%$ of the time, although the percentage of uncertain answers is summarized in the text when provided more frequently. Since multiple binary logistic regressions were used in some cases, significance levels were modified using a Bonferroni correction, where $\alpha / n(n=$ number of tests) are used to decrease the probability of false positive results.

Some questions, including land management practices and bite protection methods, asked respondents to list all possible answers. Chi-square tests (of equal variances among groups of gender and altitude class, unless otherwise indicated) were used to compare count data from responses between land use and elevation categories. All statistical analyses were conducted in Minitab v.15 software (2007).

At the end of the interview, we asked respondents to list all sources of water on their property, with researchers prompting the respondents with a long list of options that included streams, ponds, and laundry washing areas, as well as any answers beyond the list that may occur to them. All potentially suitable habitats listed by respondents were considered by researchers for comparison to "standing water" reported from earlier in the interview to assess the relationship between reported potential habitat and actual potential habitat. We also judged the approximate socioeconomic status of respondents based on housing type and signs of disposable income. According to the Ecuadorian census, approximately $38 \%$ of households lack sufficient income to provide basic necessities of life and $46 \%$ of citizens are rated under the NBI income-poverty index based on statistics collected in 2006 [29], therefore, signs of disposable income such as working televisions indicated above-average wealth.

\section{Results}

All respondents were land owners, or in the cases of larger properties, land managers; therefore, respondents in our study were expected to have a higher average economic status and live in rural settings more often than most Ecuadorian citizens. Only one residential respondent lived in an urban area (Quito), while all other respondents lived in rural regions or small communities. Although we did not formally evaluate the socioeconomic status of respondents, approximately $56 \%$ of our respondents were judged to be of a higher-than-average economic status (i.e., living in concrete houses with completed roofing and doors, and some signs of disposable income such as televisions, radios, and cars), 23\% of our respondents were judged to be of a lower socioeconomic status (i.e., living in basic housing sometimes lacking doors and sufficient roofing, with no signs of disposable income), and $20 \%$ of our respondents were judged to be very wealthy (i.e., living in large, finished homes with some degree of landscaping, on expansive properties). Greater than $90 \%$ of our respondents were ethnically identifiable as Mestizo (a mixture of Indigenous, African, and Spanish ancestry found in all regions of Ecuador), while fewer than 10 respondents were each of Indigenous, Black, or White. Five people who were approached by interviewers declined 
TABLE 2: Summary of binary logistic regression results, from answers to two statements related to knowledge of where malaria occurs and three statements related to concern about malaria and mosquitoes. Gender (reference event = male) and altitude category (reference event = below $1500 \mathrm{~m}$ ) were included as potential factors. Bonferroni-corrected significance levels are $\alpha=0.025$ for "I can get malaria..." and $\alpha$ $=0.016$ for "I am concerned about..." Positive $Z$-scores indicate that the reference event (e.g., male, below $1500 \mathrm{~m}$ ) were categories that provided the answer more often than the alternative (e.g., female, above $1500 \mathrm{~m}$ ).

\begin{tabular}{|c|c|c|c|c|c|c|}
\hline & Factor & Odds ratio & C.I. + & C.I.- & $Z$ & $P$ \\
\hline \multicolumn{7}{|l|}{ I can get malaria... } \\
\hline \multirow{3}{*}{... on my property } & Gender $(m)$ & 0.66 & 1.25 & 0.35 & -1.28 & 0.202 \\
\hline & Altitude $(b)$ & 9.10 & 18.42 & 9.10 & 6.15 & $<0.001$ \\
\hline & coefficient & & & & -5.46 & $<0.001$ \\
\hline \multirow{3}{*}{... above $3000 \mathrm{~m}$ in altitude } & Gender $(m)$ & 0.41 & 0.80 & 0.21 & -2.61 & 0.009 \\
\hline & Altitude $(b)$ & 2.46 & 4.82 & 1.26 & 2.62 & 0.009 \\
\hline & coefficient & & & & -2.41 & 0.016 \\
\hline \multicolumn{7}{|l|}{ I am concerned about... } \\
\hline \multirow{3}{*}{... insect-borne disease } & Gender $(m)$ & 0.66 & 1.17 & 0.37 & -1.42 & 0.156 \\
\hline & Altitude $(b)$ & 3.80 & 6.82 & 2.12 & 4.47 & $<0.001$ \\
\hline & coefficient & & & & 2.22 & 0.026 \\
\hline \multirow{3}{*}{... mosquitoes on my property } & Gender $(m)$ & 0.49 & 0.90 & 0.26 & -2.28 & 0.022 \\
\hline & Altitude $(b)$ & 4.33 & 8.22 & 2.28 & 4.47 & $<0.001$ \\
\hline & coefficient & & & & 3.38 & 0.001 \\
\hline \multirow{3}{*}{... malaria on my property } & Gender $(m)$ & 0.79 & 1.39 & 0.45 & -0.81 & 0.415 \\
\hline & Altitude $(b)$ & 2.87 & 5.08 & 1.62 & 3.62 & $<0.001$ \\
\hline & coefficient & & & & 2.18 & 0.029 \\
\hline
\end{tabular}

to participate in the study, therefore, the interviews did not proceed.

\section{Personal Knowledge, Belief, and Concern}

Eleven percent of respondents answering certainly above $1500 \mathrm{~m}$ stated that they could become ill with malaria on their property at present, whereas only $52.6 \%$ of respondents below $1500 \mathrm{~m}$ provided the same answer (Table 2). Of all respondents considered together, $13.3 \%$ were unsure. However, $96.4 \%$ of respondents correctly agreed with the statement that one could get malaria on the coast and/or in the Amazon region of Ecuador, with the responses not differing among genders or altitudinal categories. Agreement with the statement that one could get malaria above $3000 \mathrm{~m}$ was affected by both gender and altitude category of the respondent (Table 2): women and low-altitude dwellers were more likely to erroneously agree than men and highaltitude dwellers (women: above $1500 \mathrm{~m}$ : 29.7\%, below $1500 \mathrm{~m}$ : 55.9\%; men above $1500 \mathrm{~m}$ : $18.5 \%$, below $1500 \mathrm{~m}$ : $30.6 \%)$. Thirty-three percent of respondents were uncertain if malaria could occur above $3000 \mathrm{~m}$.

Most respondents answering certainly (89.9\%) agreed that eliminating standing water reduces the local population of mosquitoes, thereby acknowledging that they understand where larvae live. A slightly lesser percentage (83.8\%) agreed that eliminating standing water reduces the risk of malaria, thereby demonstrating an understanding that mosquito adults arise from larval stages in standing water, and the resulting adults can transmit malaria. There was no effect of gender or altitude category on responses to either statement.
Most respondents $(93.3 \%$ of those answering certainly, $74.8 \%$ total) believed that climate change was occurring, although $19.4 \%$ of were uncertain. Fewer $(75.6 \%$ of those answering certainly, $54.9 \%$ total) believed that it may be possible for malaria to move into highland regions with climate change, although $26.1 \%$ were uncertain about the possibility of this phenomenon.

A degree of concern regarding insect-borne diseases was reported significantly more often at elevations below $1500 \mathrm{~m}$ $(83.8 \%)$ than above $1500 \mathrm{~m}(57.7 \%)$, but did not differ between genders (Table 2). Concern about the presence of mosquitoes on a person's property was greater for respondents below $1500 \mathrm{~m}(87.2 \%)$ than above $1500 \mathrm{~m}(61.4 \%)$, although there were insignificant differences among genders after the Bonferroni correction (Table 2). Concern about the presence of malaria on a person's property was reported more often below $1500 \mathrm{~m}(82.3 \%)$ than above $1500 \mathrm{~m}$ (60.0\%), regardless of gender (Table 2).

\section{Land Management Perspectives for Standing Water Elimination}

Different numbers of respondents reported the presence of some type of standing water on their property depending on their land use $\left(\chi^{2}=14.82\right.$; $\left.\mathrm{df}=4 ; P=0.005\right)$. This significant difference was due mainly to cattle farmers that reported more standing water, and fish farmers that reported less standing water than expected (Figure 2). There was no difference in the reporting of standing water presence above and below $1500 \mathrm{~m}\left(\chi^{2}=0.05 ; \mathrm{df}=1 ; P=0.816\right)$. 


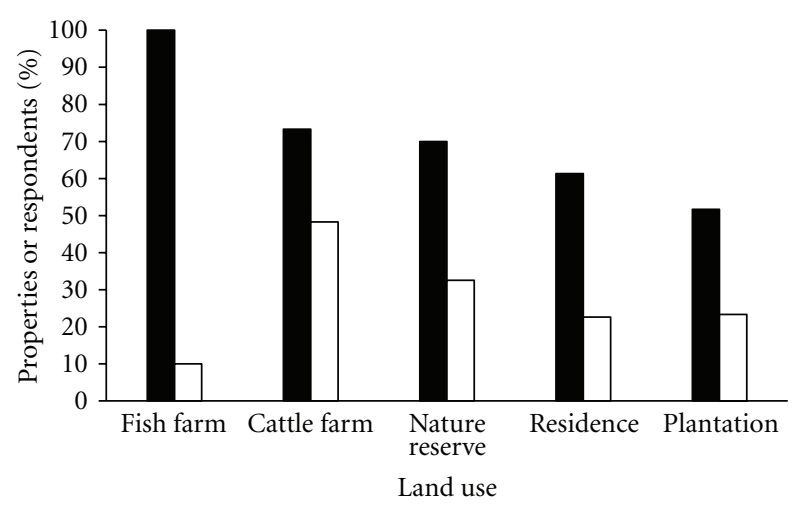

Figure 2: Proportion of respondents for each land use who reported the general presence of some type of standing water (white bars). Proportion of respondents who reported specific water bodies on their property that were judged to be potentially suitable for larvae by researchers (i.e., unmoving or very slow-moving water surfaces) (black bars).

After being asked generally if there was some type of standing water present on the property, all sources of water on the property (standing water or otherwise) were enumerated by respondents and later evaluated by the researchers as potentially suitable larval habitat or not. Figure 2 compares the presence of potentially suitable habitat (enumerated by respondents) to the rate at which the presence of some type of standing water was reported, for each land use. There was a significant association between the land use type and the proportion that reported standing water elimination versus the proportion with standing water reported in the list at the end of the interview (two-way Chi-square contingency table: $\chi^{2}=12.9, \mathrm{df}=4, P=0.012$ ), with strongest statistical effects due to the strong initial underreporting of some type of standing water by fish farmers (Figure 2). All other respondents under-reported the actual presence of standing water by about half (Figure 2). It is also possible that respondents are reporting the elimination of some standing water, though not all sources of water.

The types of standing water observed on each of the different land uses are summarized in Figure 3. Approximately $77.5 \%$ of fish farms had at least one fish pond or tank, with an area of stable water surface that could potentially support mosquito larvae (Figure 3(a)). Ponds were the most common type of standing water for nature reserves (Figure 3(c)), while irrigation canals or inland ditches were the most common for cattle farms (Figure 3(b)), residences (Figure 3(d)), and plantations (Figure 3(e)). It should be noted that not all standing water types listed would be suitable for Anopheles mosquito larvae, although they may be suitable for other species of mosquitoes.

The percentage of respondents that presently eliminate their standing water differed significantly among land uses $\left(\chi^{2}=16.1 ; \mathrm{df}=4 ; P=0.003\right)$, with the strongest effect due to a smaller number of cattle farmers than expected reporting that they eliminate standing water (Figure 4(a)). However, the proportions of respondents that eliminate standing water for each land use did not differ between altitude categories (above/below $1500 \mathrm{~m})\left(\chi^{2}=2.4 ; \mathrm{df}=4 ; P=0.655\right)$ (Figure 4(a)).

Reasons provided for not eliminating standing water were enumerated (Figure 4(b)), and approximately twice the number of reasons were given by respondents below $1500 \mathrm{~m}$ than above (Figure 4(b)). The top three reasons provided were logistical difficulty (6.2\%), lacking human assistance (3.5\%), and lacking time to eliminate the water (3.5\%). Water being "natural" was only provided as a reason for not eliminating water by nature reserves. Not being able to eliminate standing water due to economic use of the water body was reported for rice farms and fish ponds below $1500 \mathrm{~m}$.

Four possible motivations that might encourage respondents to eliminate standing water were compared and all four appear to be strong motivators to eliminate water: (1) the presence of malaria nearby $(95.3 \%)$, (2) financial support to eliminate water (93.9\%), (3) increased frequency of mosquito bites (93.3\%), and (4) recommendations by government or medical authorities (89.9\%). There was no statistical difference in agreement with motivational sources between genders or altitude categories.

\section{Mosquito Bite Protection}

Respondents were asked if they currently use any form of mosquito bite protection, and if they would use protection if they visited an area known to have malaria. Use of some type of malaria protection differed between altitude categories as well as current use versus use for a known malaria-endemic region, although bite prevention did not differ between genders (Table 3 ). Current use of protection was higher below than above $1500 \mathrm{~m}$ (Figure 5; Table 3). Respondents reported that they would use malaria protection more often in an area with known malaria than what they currently use, even if they already live in a possibly malaria-endemic area (below $1500 \mathrm{~m}$ ) (Figure 5; Table 3).

Methods used to prevent mosquito bites are summarized in Figure 6. The most commonly used prevention methods above $1500 \mathrm{~m}$ are (1) insecticides for the home, (2) long sleeves, and (3) chemical repellent (Figure 6(a)). If those respondents visited an area with known malaria, (1) bed nets, (2) long sleeves, and (3) insecticides for the home would be the most commonly used (Figure 6(b)). The most common types of prevention methods used below $1500 \mathrm{~m}$ are (1) bed nets, (2) insecticides in the home, (3) chemical repellent, (4) long sleeves, (5) screen or curtain on doors and windows, and (6) chlorine or chemicals in standing water (Figure 6(c)). The same top six prevention methods are listed by respondents for hypothetical travel to an area with known cases of malaria, although the order in which they are listed is different (Figure 6(d)) The less-often reported prevention methods for respondents living below $1500 \mathrm{~m}$ include calling the Sistema Nacional de Eradicación de Malaria (government agency), use of a fan or air conditioning, or a community effort to eliminate mosquito habitat, all of which have the potential to prevent mosquito bites. 


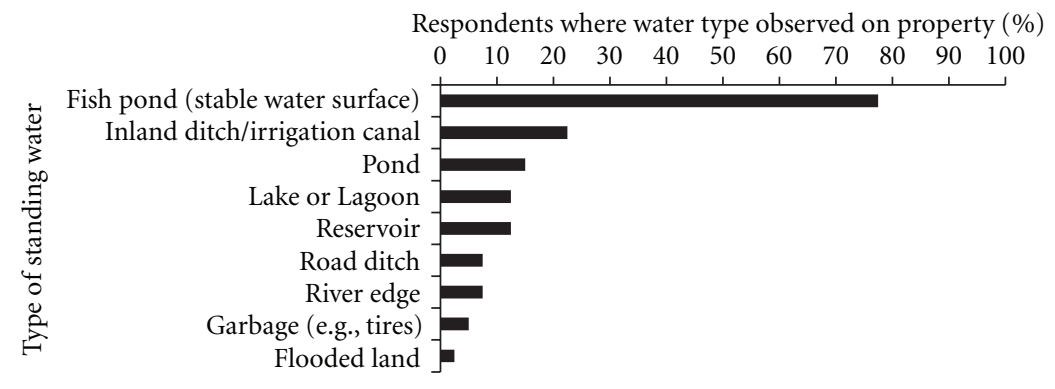

(a) Fish farm.

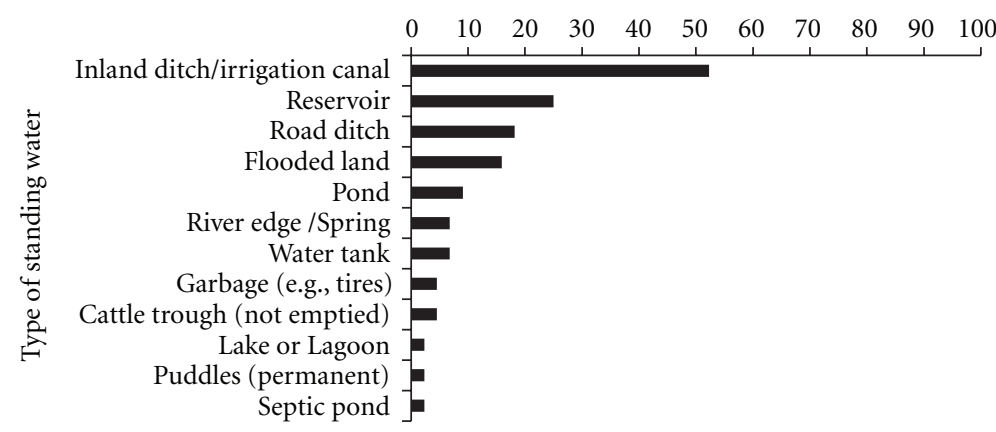

(b) Cattle farm.

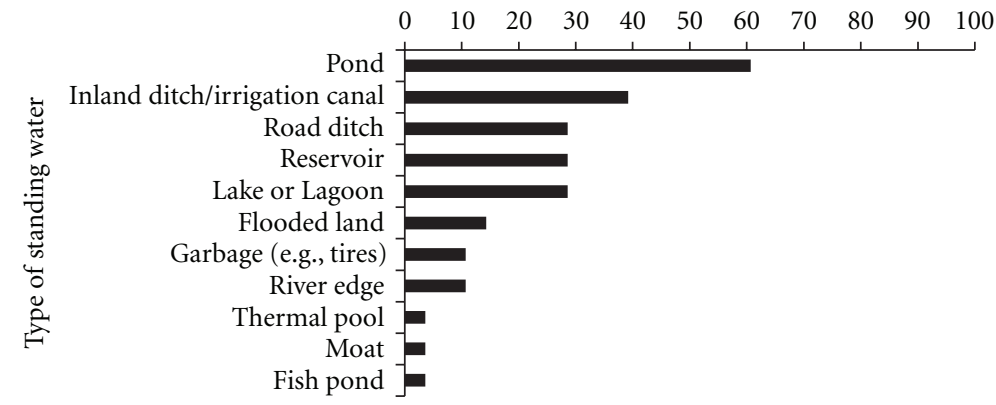

(c) Nature reserve.

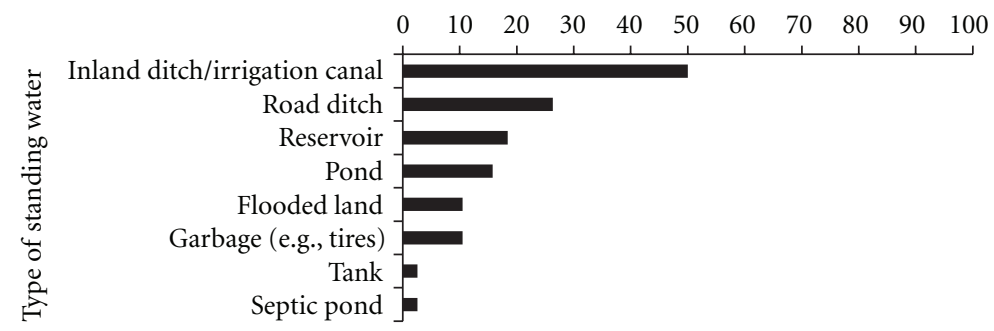

(d) Residence.

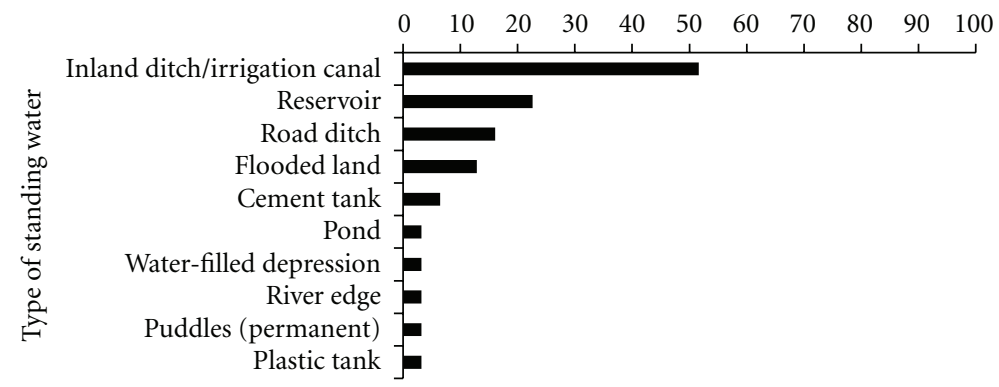

(e) Plantation

Figure 3: Types of standing water from all water types enumerated at the end of the interview, divided by land use (a)-(e). For each land use, water type is ordered from most common to least common. 


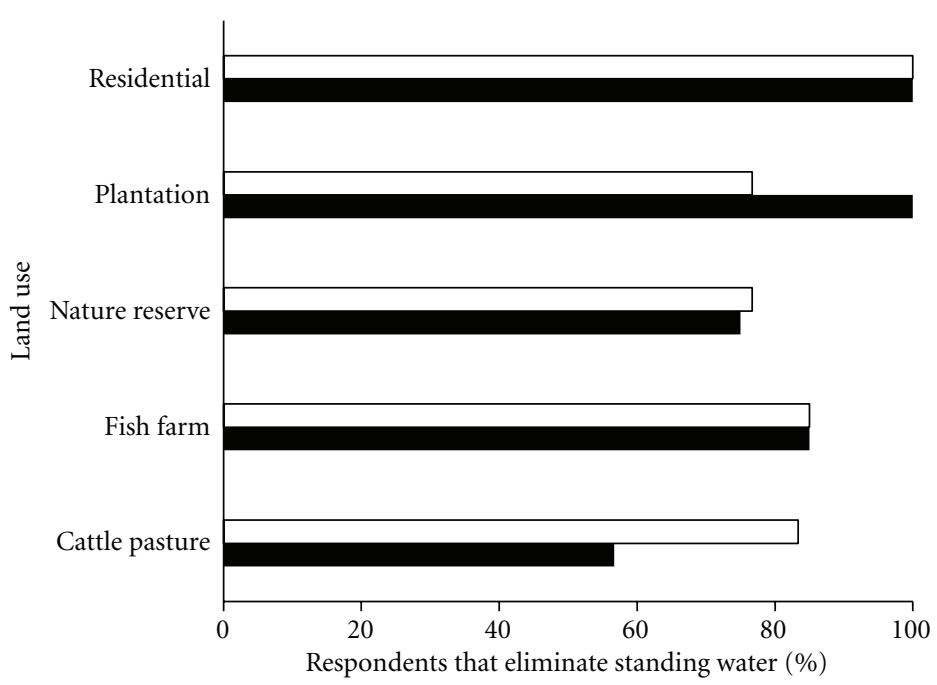

(a)

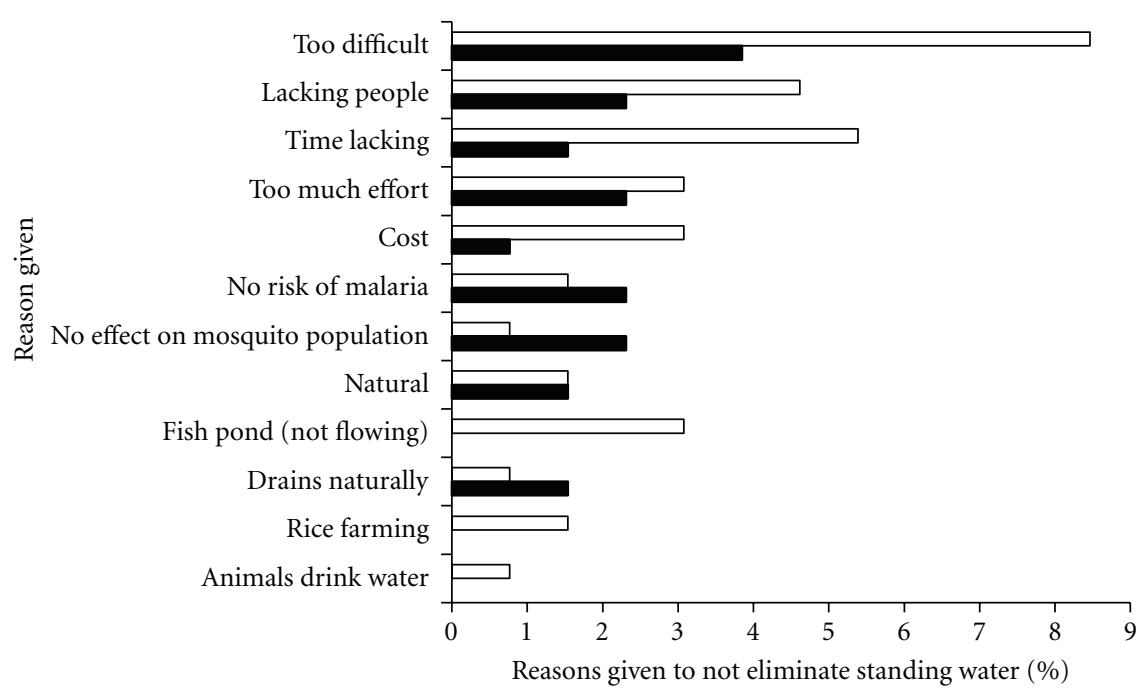

(b)

FIGURE 4: Percentage of respondents above (black bars) and below $1500 \mathrm{~m}$ (white bars) who (a) presently eliminate standing water, by land use or (b) provide a reason for not eliminating standing water on their property. Reasons are enumerated from most common to least common.

\section{Discussion}

Since the present study focuses on land owners and land managers who are of a higher socioeconomic status than the average Ecuadorian citizen, it is also likely that respondents had received more education than average, which we expect to relate to a better understanding of the topics under discussion. Therefore, the present study should not be extrapolated to the knowledge, attitudes, and beliefs of all Ecuadorians, but rather should provide a baseline of these factors among land owners and/or land managers, that is, the decision makers for larval habitat modification in the overall landscape.

Although most participants in this study correctly identified general regions where malaria does and does not occur in their country, it is troubling that $52.6 \%$ of respondents below $1500 \mathrm{~m}$ did not feel that they were at risk of contracting malaria on their property. We did not formally discuss personal experiences with malaria with respondents, which would likely explain some of the variation in this response, and is one of the shortcomings of our study. Although a small percentage of these are probably not at immediate risk [7], several respondents appeared to deny personal risk despite anecdotally providing us with examples of neighbours or nearby towns with recent malaria cases. Another explanation might be that respondents feel that malaria is a controllable risk, and they might not be susceptible to infection because they use mosquito bite protection, for example, [30]. The current findings might indicate that lowland residents would benefit from an educational program in their community that provides updated data concerning their immediate and potential risk of malaria. 
TABle 3: Summary of binary logistic regression results, comparing the use of a type of mosquito protection between genders (male = reference event) and altitude categories (below = reference event); what is currently used by the respondent versus what respondents state that they would use for travel to a region with confirmed cases of malaria (travel to region with confirmed malaria $=$ reference event). Positive $Z$-scores indicate that the reference event (e.g., male, below $1500 \mathrm{~m}$, in an area known to have malaria) were categories that provided the answer more often than the alternative (e.g., female, above $1500 \mathrm{~m}$, what is used currently).

\begin{tabular}{lccccc}
\hline Factor & $\begin{array}{c}\text { Odds } \\
\text { ratio }\end{array}$ & C.I.+ & C.I. - & $Z$ & $P$ \\
\hline Gender $(m)$ & 0.88 & 1.43 & 0.54 & -0.51 & 0.610 \\
$\begin{array}{l}\text { Altitude }(b) \\
\begin{array}{l}\text { Currently versus if } \\
\text { known malaria } \\
(\text { known malaria) }\end{array}\end{array}$ & 5.10 & 8.60 & 3.02 & 6.10 & $<0.001$ \\
Constant & & 16.77 & 5.17 & 7.43 & $<0.001$ \\
\hline
\end{tabular}

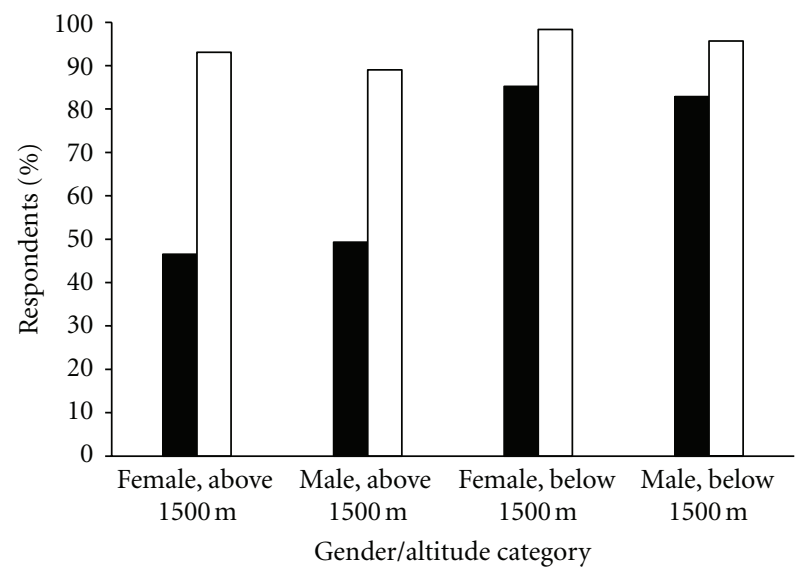

Figure 5: Percentage of respondents who use at least one type of mosquito bite prevention method (black bars) or would use at least one type of mosquito bite-prevention method during travel to an area known to have malaria cases (white bars). Bars are categorized by gender and altitude category.

Generally, most respondents understood that standing water could increase mosquito populations, and thereby malaria incidence. Most also believed that climate change is under way. Along the same lines, a large number were also receptive to the possibility of highland regions becoming affected by malaria in the future with climate change. Such a widespread open-mindedness would be useful for rapid identification of malaria cases and acceptance of risk should malaria spread to previously-unaffected highland regions due to meteorological or other causes. As we would predict from experience, those at altitudes lower than $1500 \mathrm{~m}$ reported being more concerned by the presence of mosquitoes, malaria, and other types of insect-borne disease.

Substantially, fewer respondents reported the presence of standing water on their property early in the interview than those reported later in the interview. Although part of this could be due to denial, or to a lack of awareness of their own property, a more likely reason for many respondents to deny the presence of water could be the too-specific definition of "standing water" for mosquito habitat. Many respondents did not likely consider often-flowing water types such as irrigation canals to be standing water. Anecdotally, several respondents talked about the necessity of swamps and marshes for mosquito habitat, whereas the most commonly observed standing water types on properties were ponds, reservoirs, and irrigation canals. Therefore, we suggest that the malaria education programs that target standing water elimination need to define potential larval habitat as any water where the surface of the water is not moving or moving slowly, rather than the more typical "standing water," or "aguas estancadas." Since the type of standing water available is dependent on land use, it is also important for future studies to more extensively define suitable versus unsuitable habitat types for Anopheles larvae to include those that could be considered to flow, such as irrigation canals and roadside ditches. Although Ecuadorian land owners/managers could be motivated to eliminate standing water through direct observation or advice from authorities, the largest reason provided for not eliminating the water is difficulty (usually due to topography) - a practical problem that would be expensive to address.

A large number of respondents below $1500 \mathrm{~m}$ used some type of mosquito protection (84.0\%). Bed nets were the most prevalent mosquito bite prevention method in low-altitude regions $(66.4 \%)$, and were more commonly used than in a community in northern Coastal Ecuador (23\%), lowland Colombia (59\%), or rural Uganda (26\%), possibly due to greater socioeconomic standing among our interviewed landowners/managers than other community members [3, $22,31]$. We did not personally assess whether or not the respondents' bed nets were in good condition, or if they were treated with insecticide, which is important for bite prevention or might help to reduce resting populations of adult mosquitoes within homes $[32,33]$. Both of these factors could be avenues for future research. The numbers might have also been inflated due to the common use of bed nets to prevent the annoyance of mosquitoes rather than malaria [34].

Insecticides within the home, including sprays, were also often employed in low-altitude areas (57.5\%), similar to communities in the Colombian Pacific coast (57\%) [3]. Their common usage is positive, since one study in the highlands of Kenya reports that indoor residual house-spraying actually reduces infection rates more than bed nets [35]. Interestingly, mosquito spirals were not presently used by Ecuadorian respondents, despite 60\% usage in the Colombian Pacific coast [3].

Mosquito protection methods that would be employed by Ecuadorian land owners/managers during travel to a malaria-endemic area differ slightly from those reported in the travel medical literature. Although $80-90 \%$ of our respondents state that they would use a bed net in a malariaendemic area of their own country, in one study only $58 \%$ of foreign travelers to a malaria-endemic area would do the same [36]. However, a higher proportion of travelers in the same paper [36] would use long sleeves (93\%) and chemical 


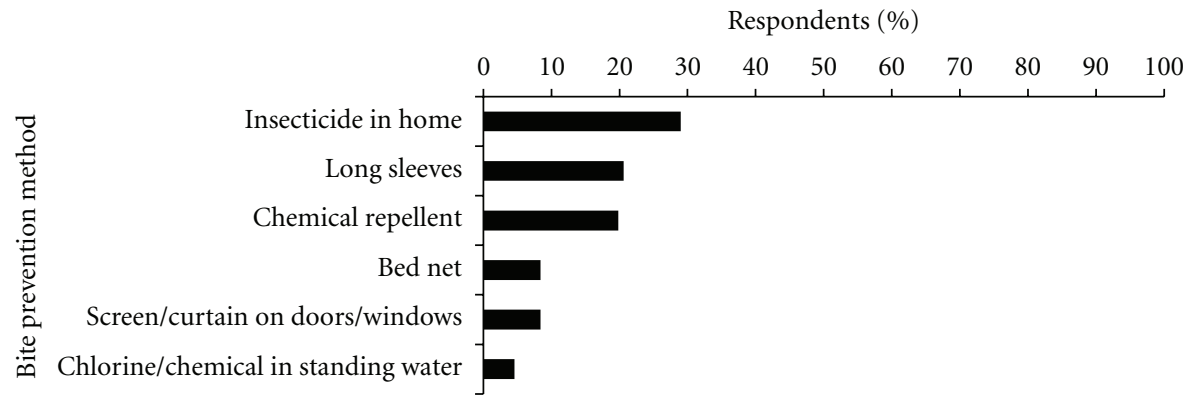

(a)

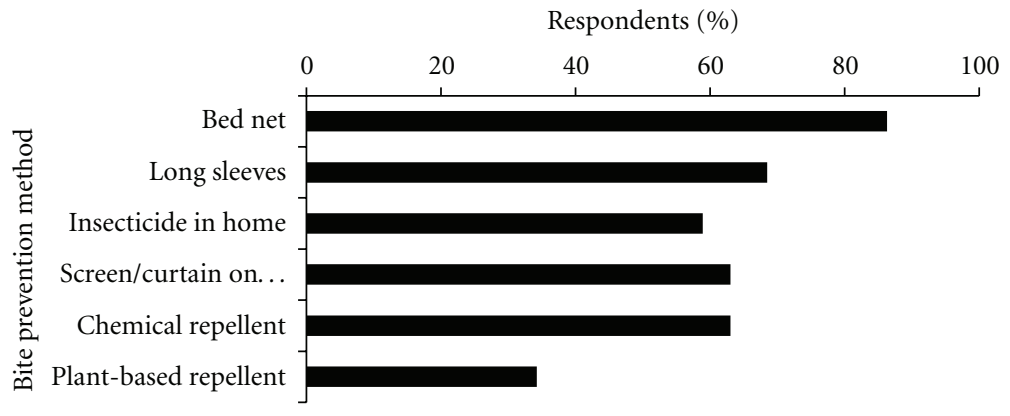

(b)

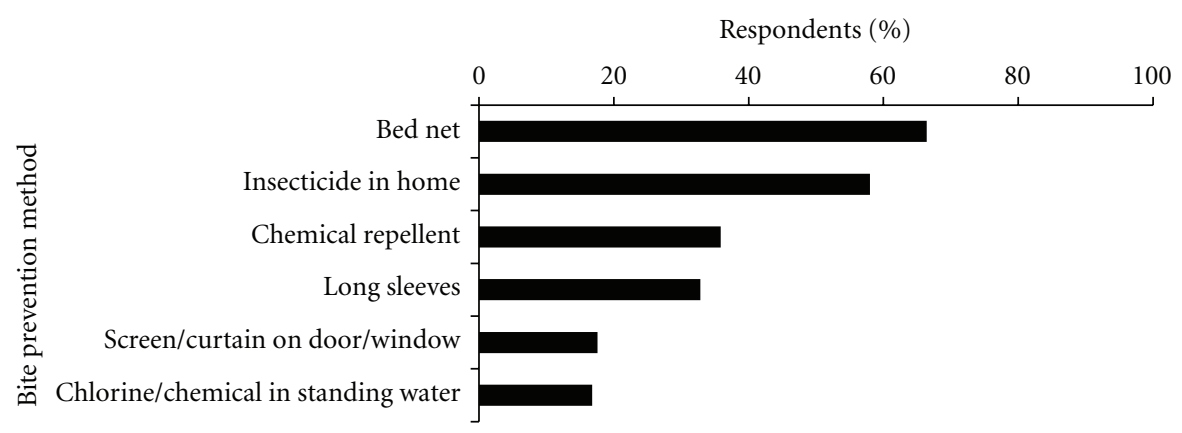

(c)

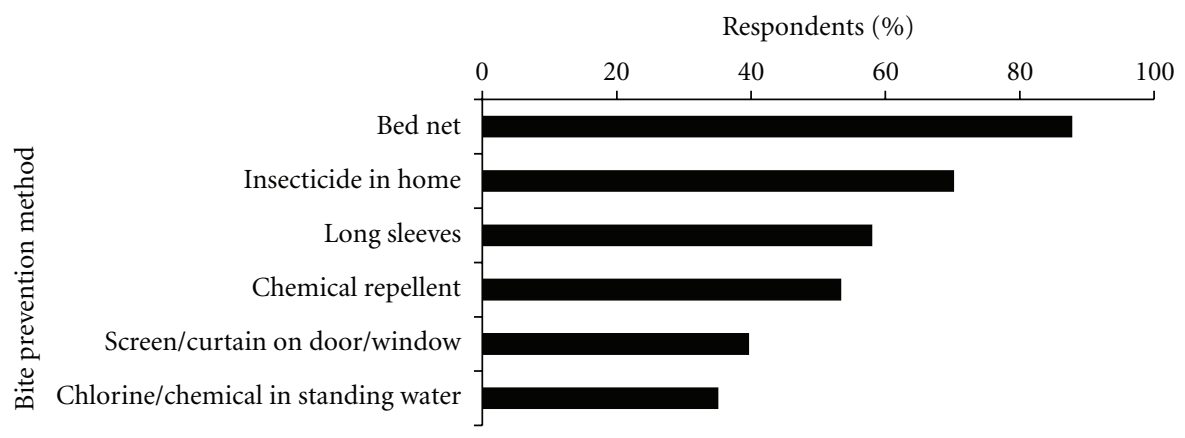

(d)

FIGURE 6: Top six bite prevention methods mentioned among respondents: (a) what is used currently above $1500 \mathrm{~m}$, (b) what would be used for travel to a malaria-endemic area (respondents above $1500 \mathrm{~m}$ ), (c) what is used currently below $1500 \mathrm{~m}$, and (d) what would be used for travel to a malaria-endemic area (respondents below $1500 \mathrm{~m}$ ).

repellent $(90 \%)$ than our respondents (approximately 50 $60 \%$ ). Travelers from developed countries also rely heavily on chemical prophylaxis for malaria prevention [36-38], while fewer than $5 \%$ of our respondents would use it for travel into a region with known cases of malaria.
We had expected more folklore-based and traditional medicine and mosquito prevention methods from our respondents, since it is known that plant-based malaria prevention and treatments are still quite common in parts of Ecuador, for example, $[4,22,39]$ and in Colombia 
$[3,23]$, as well as in rural parts of Africa [31, 40, 41]. This may have been in part due to the higher average socioeconomic status of our respondents, who may have been more able to purchase nontraditional mosquito bite prevention methods, such as DEET-based chemical repellent. Some of the plant-based repellents that were mentioned by respondents included citrus fruits (e.g., lemon juice) and menthol. The use of smoke as a mosquito repellent included the traditional burning of termite nests in Amazonian regions, as well as burning "palo santo," wood from the Bursera graveolens tree that is common on the coast.

Further studies are required to evaluate the malaria KAP of Ecuadorian citizens who do not own properties in Ecuador, as well as citizens residing elsewhere in the Andes, and to elucidate cultural and educational differences among perceptions of malaria risk. The present study focused on individual responses, although community approaches to larval source reduction can also play an important role in habitat elimination and highland malaria prevention.

\section{Conclusions}

A large proportion of land owners/managers presented a good understanding of the occurrence of malaria on the Ecuadorian coast or in Amazonia and were able to form a basic causative link between standing water, mosquitoes, and malaria. However, about half of the landowners/managers in potential risk areas (i.e., altitudes $<1500 \mathrm{~m}$ ) did not believe that it was possible to become ill from malaria on their own property. Most respondents expressed a belief in climate change and were open-minded to the possibility of anopheline mosquitoes moving into higher-altitude regions.

Different generalized land uses provided different types of standing water, which may vary in suitability for anopheline larvae. Most respondents reported eliminating standing water on their property. When it was not reported to be eliminated, respondents were most often unable to eliminate water due to logistical difficulties. In many cases, respondents reported eliminating standing water despite later reporting sources of standing water that might provide potentially suitable anopheline habitat. This may have been due to partial, but not thorough, elimination of standing water.

Most respondents in lowland (at-risk) regions use some type of mosquito bite prevention, most commonly bed nets. During hypothetical travel to a known malaria-endemic region, both lowlanders and highlanders would increase their overall use of bite prevention. Therefore, residents of malaria-endemic regions might be expected to increase their use of prevention if informed that their property lies in a malaria-endemic area.

Generally, it is hoped that the findings of this study will assist malaria control organizations by providing useful data to improve the efficiency of potential educational programs. While knowledge of malaria's occurrence patterns is strong in Ecuador, even in highland regions, it might be necessary to inform residents of actual malaria risk, so that risk does not continue to be underestimated. Although most respondents understand that there is a link between standing water and malaria, the definition of standing water is often too restrictive and does not encompass all potential mosquito habitats on a person's property. Ecuadorian land owners/managers appear to be strongly motivated to eliminate mosquito habitat on their property, and when they do not eliminate standing water, it is usually due to factors beyond their control (difficulty or limited financial resources). Most at-risk Ecuadorian land owners/managers currently use mosquito bite protection methods, although the use of protection might increase if they were informed that they live in a potentially malarious area.

\section{Acknowledgments}

The authors are extremely grateful to their field assistants Santiago Caizapanta, Julio Rivera, and Leonardo Ortega, as well as their Ecuadorian collaborators Renato León and Francisco Morales at USFQ and Clifford Keil at PUCE. They also thank Drs. John Middleton, Liette Vasseur, Glenn Tattersall, and an anonymous reviewer for comments on the experimental design and this paper, and Edmundo Caizapanta and the SNEM of Ecuador for helpful comments in the field. This study was funded by an NSERC PGS Award to Lauren L. Pinault, an NSERC Discovery Grant to Fiona F. Hunter and an IDRC Doctoral Research Award to Lauren L. Pinault. Importantly, they also wish to thank all of their study participants for their generosity of time and keen insight.

\section{References}

[1] Y. Rubio-Palis and R. H. Zimmerman, "Ecoregional classification of malaria vectors in the neotropics," Journal of Medical Entomology, vol. 34, no. 5, pp. 499-510, 1997.

[2] A. S. Gagnon, K. E. Smoyer-Tomic, and A. B. G. Bush, "The El Niño southern oscillation and malaria epidemics in South America," International Journal of Biometeorology, vol. 46, no. 2, pp. 81-89, 2002.

[3] T. Nieto, F. Méndez, and G. Carrasquilla, "Knowledge, beliefs and practices relevant for malaria control in an endemic urban area of the Colombian Pacific," Social Science and Medicine, vol. 49, no. 5, pp. 601-609, 1999.

[4] W. Ruiz and A. Kroeger, "The socioeconomic impact of malaria in Colombia and Ecuador," Health Policy and Planning, vol. 9, no. 2, pp. 144-154, 1994.

[5] H. Brochero and M. L. Quiñones, "Retos de la entomología médica para la vigilancia en salud pública en Colombia: reflexión para el caso de malaria," Biomédica, vol. 28, no. 1, pp. 18-24, 2008.

[6] N. Espinoza López, L. Triviño Yépez, J. Alarcón y Alvaredo, and L. Vélez Nieto, "Contribución historica y actual del servicio nacional de control de enfermedades transmitidas por vectores (SNEM) para el mejoramiento de la salud y calidad de vida de los ecuatorianos en relación a las enfermedades transmitidas por vectores artrópodos," in Sistema Nacional de Eradicaccion de Malaria, p. 21, Guayaquil, Ecuador, 2009.

[7] "Datos malaricos del acumulado de los meses de enero a diciembre, area técnica epidemiologia," in Sistema Nacional de Eradicacion de Malaria, Guayaquil, Ecuador, 1997-2008.

[8] R. Levi-Castillo, "Anopheles pseudopunctipennis in the Los Chillos valley of Ecuador," Journal of Economic Entomology, vol. 38, no. 5, pp. 385-390, 1945. 
[9] W. J. M. Martens, L. W. Niessen, J. Rotmans, T. H. Jetten, and A. J. McMichael, "Potential impact of global climate change on malaria risk," Environmental Health Perspectives, vol. 103, no. 5, pp. 458-464, 1995.

[10] P. R. Epstein, H. F. Diaz, S. Elias et al., "Biological and physical signs of climate change: focus on mosquito-borne diseases," Bulletin of the American Meteorological Society, vol. 79, no. 3, pp. 409-417, 1998.

[11] S. W. Lindsay and W. J. M. Martens, "Malaria in the African highlands: past, present and future," Bulletin of the World Health Organization, vol. 76, no. 1, pp. 33-45, 1998.

[12] P. Reiter, "Climate change and mosquito-borne disease," Environmental Health Perspectives, vol. 109, no. 1, pp. 141-161, 2001.

[13] S. I. Hay, D. J. Rogers, S. E. Randolph et al., "Hot topic or hot air? Climate change and malaria resurgence in East African highlands," Trends in Parasitology, vol. 18, no. 12, pp. 530-534, 2002.

[14] A. R. Moreno, "Climate change and human health in Latin America: drivers, effects, and policies," Regional Environmental Change, vol. 6, no. 3, pp. 157-164, 2006.

[15] M. E. Loevinsohn, "Climatic warming and increased malaria incidence in Rwanda," The Lancet, vol. 343 , no. 8899, pp. 714 718, 1994.

[16] M. A. Malakooti, K. Biomndo, and G. D. Shanks, "Reemergence of epidemic malaria in the highlands of western Kenya," Emerging Infectious Diseases, vol. 4, no. 4, pp. 671-676, 1998.

[17] K. A. Lindblade, E. D. Walker, A. W. Onapa, J. Katungu, and M. L. Wilson, "Land use change alters malaria transmission parameters by modifying temperature in a highland area of Uganda," Tropical Medicine and International Health, vol. 5, no. 4, pp. 263-274, 2000.

[18] T. Rutar, E. J. Baldomar Salgueiro, and J. H. Maguire, "Introduced Plasmodium vivax malaria in a Bolivian community at an elevation of 2,300 meters," American Journal of Tropical Medicine and Hygiene, vol. 70, no. 1, pp. 15-19, 2004.

[19] F. Lardeux, P. Loayza, B. Bouchité, and T. Chavez, "Host choice and human blood index of Anopheles pseudopunctipennis in a village of the Andean valleys of Bolivia," Malaria Journal, vol. 6, 8 pages, 2007.

[20] L. Pinault and F. Hunter, "New highland distribution records of multiple Anopheles species in the Ecuadorian Andes," Malaria Journal, vol. 10, 236 pages, 2011.

[21] K. A. Lindblade, J. Katungu, and M. L. Wilson, "Fever and malaria in highland Uganda," Transactions of the Royal Society of Tropical Medicine and Hygiene, vol. 95, no. 5, pp. 502-503, 2001.

[22] A. Kroeger and J. Alarcon, Malaria en Ecuador y Peru y estrategías alternativas de control, Ediciones Abya-Yala, Quito, Ecuador, 1993.

[23] F. Pineda and C. A. Agudelo, "Percepciones, actitudes y prácticas en malaria en el Amazonas Colombiano," Révista de Salud Pública, vol. 7, no. 3, pp. 339-348, 2005.

[24] M. Tanner and C. Vlassoff, "Treatment-seeking behaviour for malaria: a typology based on endemicity and gender," Social Science and Medicine, vol. 46, no. 4-5, pp. 523-532, 1998.

[25] R. Lipowsky, A. Kroeger, and M. L. Vazquez, "Sociomedical aspects of malaria control in Colombia," Social Science and Medicine, vol. 34, no. 6, pp. 625-637, 1992.

[26] E. Sevilla-Casas, "Human mobility and malaria risk in the Naya river basin of Colombia," Social Science and Medicine, vol. 37, no. 9, pp. 1155-1167, 1993.

[27] D. J. Bradley, D. C. Warhurst, P. Barrett et al., "Fortnightly review: malaria prophylaxis: guidelines for travellers from
Britain,” British Medical Journal, vol. 310, no. 6981, pp. 709714, 1995.

[28] G. E. Lenski and J. C. Leggett, "Caste, class, and deference in the research interview," The American Journal of Sociology, vol. 65, no. 5, pp. 463-467, 1960.

[29] L. E. Cañizares and G. M. Lopez, Ecuador en Cifras, Instituto Nacional de Estatisticas y Censos, Government of Ecuador, Quito, Ecuador, 2011.

[30] N. D. Weinstein, "Why it won't happen to me: perceptions of risk factors and susceptibility," Health Psychology, vol. 3, no. 5, pp. 431-457, 1984.

[31] F. Nuwaha, "People's perception of malaria in Mbarara, Uganda," Tropical Medicine and International Health, vol. 7, no. 5, pp. 462-470, 2002.

[32] S. E. Clarke, C. Bøgh, R. C. Brown, M. Pinder, G. E. L. Walraven, and S. W. Lindsay, "Do untreated bednets protect against malaria?" Transactions of the Royal Society of Tropical Medicine and Hygiene, vol. 95, no. 5, pp. 457-462, 2001.

[33] K. A. Lindblade, J. E. Gimnig, L. Kamau et al., "Impact of sustained use of insecticide-treated bednets on malaria vector species distribution and culicine mosquitoes," Journal of Medical Entomology, vol. 43, no. 2, pp. 428-432, 2006.

[34] C. A. Miguel, V. L. Tallo, L. Manderson, and M. A. Lansang, "Local knowledge and treatment of malaria in Agusan del Sur, the Philippines," Social Science and Medicine, vol. 48, no. 5, pp. 607-618, 1999.

[35] H. L. Guyatt, S. K. Corlett, T. P. Robinson, S. A. Ochola, and R. W. Snow, "Malaria prevention in highland Kenya: indoor residual house-spraying vs. insecticide-treated bednets," Tropical Medicine and International Health, vol. 7, no. 4, pp. 298303, 2002.

[36] S. Toovey, A. Jamieson, and M. Holloway, “Travelers' knowledge, attitudes and practices on the prevention of infectious diseases: results from a study at Johannesburg International Airport," Journal of Travel Medicine, vol. 11, no. 1, pp. 16-22, 2004.

[37] K. Van Herck, J. Zuckerman, F. Castelli, P. Van Damme, E. Walker, and R. Steffen, "Travelers' knowledge, attitudes, and practices on prevention of infectious diseases: results from a pilot study," Journal of Travel Medicine, vol. 10, no. 2, pp. 7578, 2003.

[38] A. Wilder-Smith, N. S. Khairullah, J. H. Song, C. Y. Chen, and J. Torresi, "Travel health knowledge, attitudes and practices among australasian travelers," Journal of Travel Medicine, vol. 11, no. 1, pp. 9-15, 2004.

[39] D. Pedersen and C. Coloma, "Traditional medicine in Ecuador: the structure of the non-formal health systems," Social Science and Medicine, vol. 17, no. 17, pp. 1249-1255, 1983.

[40] S. H. Muela, J. M. Ribera, and M. Tanner, "Fake malaria and hidden parasites-the ambiguity of malaria," Anthropology and Medicine, vol. 5, no. 1, pp. 43-61, 1998.

[41] D. S. Tarimo, G. K. Lwihula, J. N. Minjas, and I. C. Bygbjerg, "Mothers' perceptions and knowledge on childhood malaria in the holendemic Kibaha district, Tanzania: implications for malaria control and the IMCI strategy," Tropical Medicine and International Health, vol. 5, no. 3, pp. 179-184, 2000. 


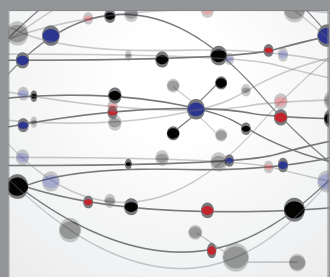

The Scientific World Journal
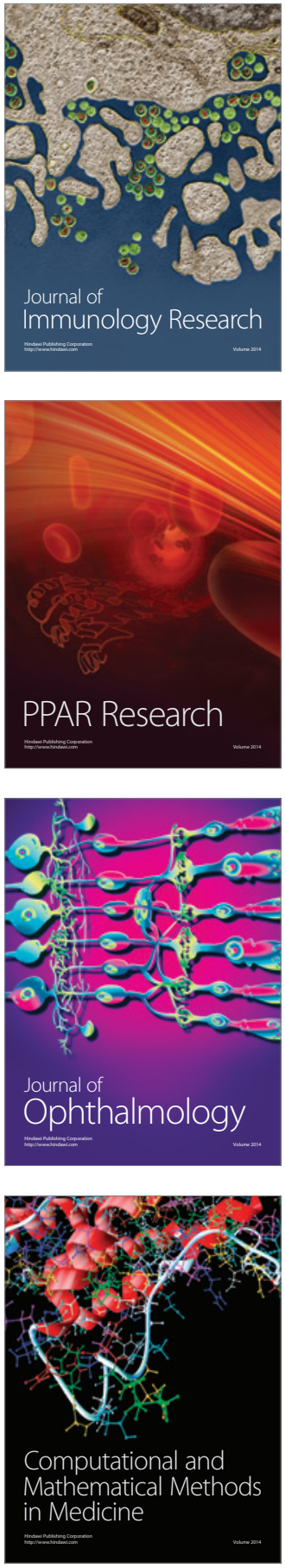

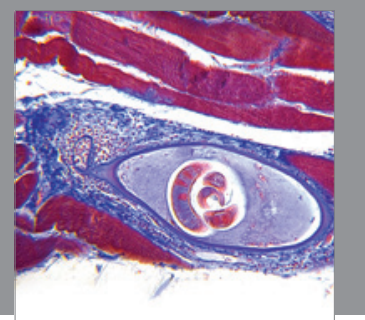

Gastroenterology

Research and Practice
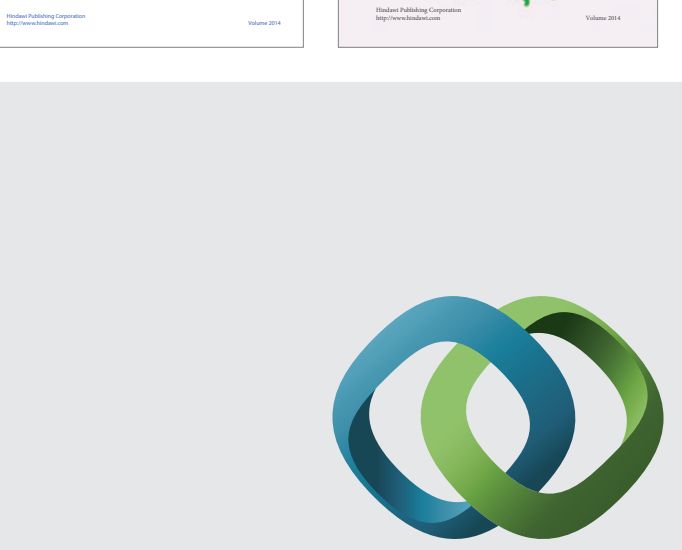

\section{Hindawi}

Submit your manuscripts at

http://www.hindawi.com
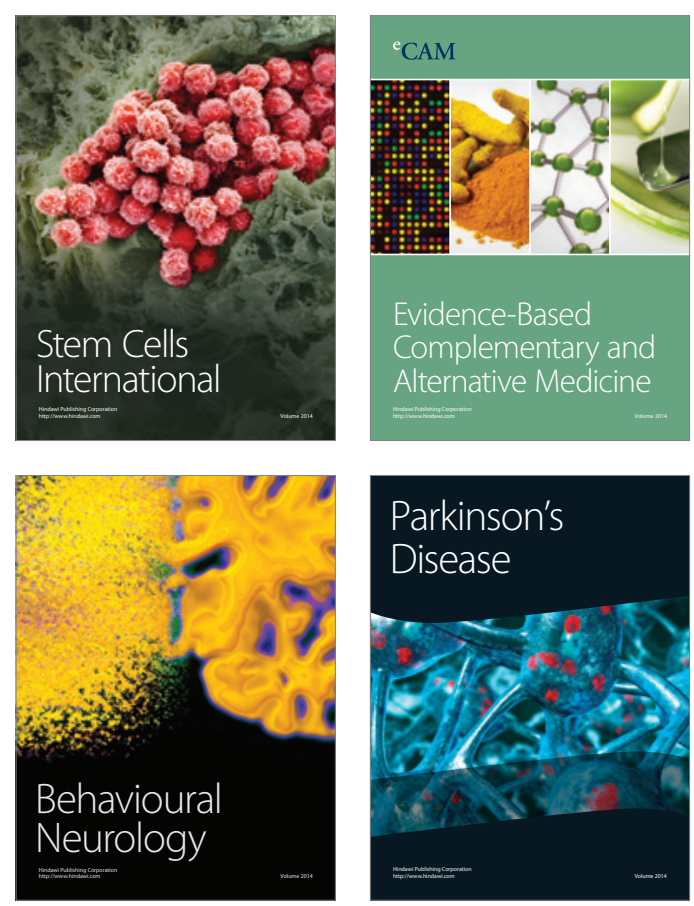

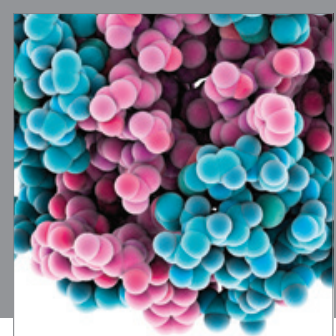

Journal of
Diabetes Research

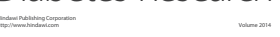

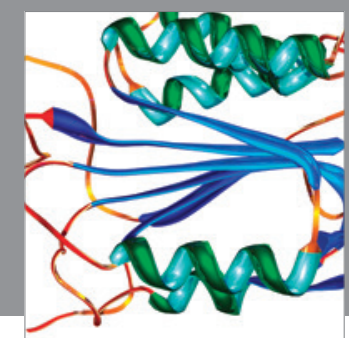

Disease Markers
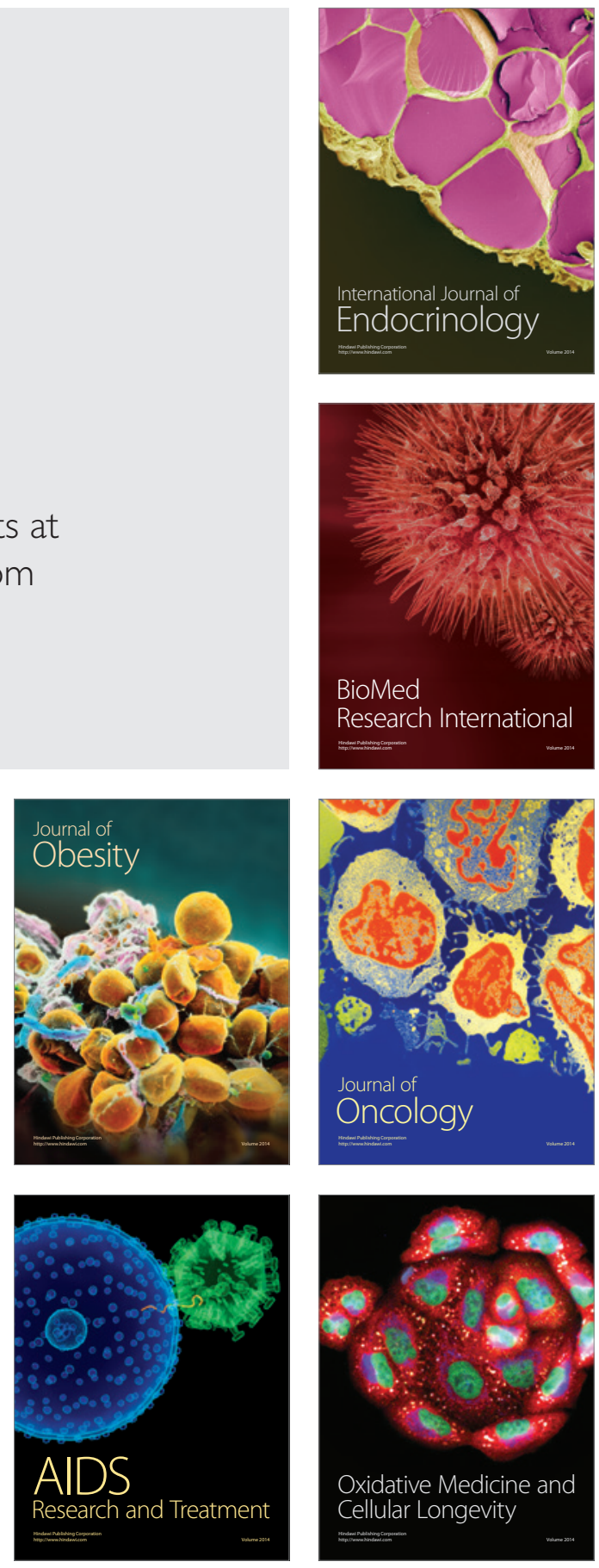